Review

\title{
Is research keeping up with changes in landscape policy? A review of the literature
}

\author{
Elisabeth Conrad ${ }^{\mathrm{a}}$, Mike Christie ${ }^{\mathrm{b}}$, Ioan Fazey ${ }^{\mathrm{c}, *}$ \\ a Institute of Earth Systems, Chemistry Building, University of Malta, Msida MSD2080, Malta \\ ${ }^{\mathrm{b}}$ Institute of Biological, Environmental and Rural Sciences, Aberystwyth University, Penglais, Aberystwyth, Ceredigion, SY23 3DA UK Wales, United Kingdom \\ ${ }^{\mathrm{c}}$ School of Geography and Geosciences, University of St. Andrews, Irvine Building, North Street, St. Andrews, KY16 9AL Fife, Scotland, United Kingdom
}

\section{A R T I C L E I N F O}

\section{Article history:}

Received 15 September 2010

Received in revised form 8 March 2011

Accepted 10 April 2011

Available online $\mathrm{xxx}$

\section{Keywords:}

Landscape policy

Landscape research

European Landscape Convention

Participation

\begin{abstract}
A B S T R A C T
Several innovative directions for landscape policy development and implementation have emerged over recent years. These include: (i) an expansion of scope to include all landscape aspects and landscape types, (ii) an increased emphasis on public participation, (iii) a focus on designing measures appropriate for different contexts and scales, and (iv) encouraging support for capacity-building. In this paper, we evaluate the extent to which these policy directions are reflected in the practice of academic landscape research. We evaluate all research papers published in three leading landscape journals over six years, as well as published research papers relating directly to the European Landscape Convention. The latter, which was adopted in 2000 , establishes a framework for landscape protection, planning and management in Europe and is to date the only international legal instrument of its kind. Results indicate that whilst policy innovations do not appear to be a major stimulus for academic research, studies nevertheless address a range of landscape aspects, types and scales (albeit with a slight bias towards bio-physical landscape aspects). However, geographical representativeness of research is weak and dominated by the United States and northern/western Europe, and research capacity likewise appears to be unevenly distributed. Landscape research is also limited in the extent to which it involves stakeholders or develops innovative methods for doing so, notwithstanding that this remains a key challenge for policy-makers. Results point to the potential for landscape research to address areas (topical and geographical) which have received little attention to date, as well as suggesting mutual benefits of stronger links between policy and academia.
\end{abstract}

(ㄷ) 2011 Elsevier Ltd. All rights reserved.

\section{Introduction}

Policy and academia have often been conceived of as two distinct cultures (Alison et al., 2004; George, 1994), with different objectives and priorities, shaped by the implicit expectations and values of their respective environments (Curtis, 2004; George, 1994; Nye, 2008; Ross, 1994). Nevertheless, it is essential that there are strong linkages between the worlds of academics and practitioners (Hughes et al., 2008; Moats and McLean, 2009), to ensure that (i) academic research is of pragmatic relevance, and (ii) policy development is informed by robust academic work and rigour (Fazey et al., 2004; Haggerty, 2004; Pullin, 2004). For this to occur, there

\footnotetext{
* Corresponding author. Tel.: +4401334 463937; fax: +44 01334463949.

E-mail addresses: elisabeth.conrad@um.edu.mt (E. Conrad), mec@aber.ac.uk (M. Christie), ioan.fazey@st-andrews.ac.uk (I. Fazey).
}

is a need for policy and research to co-evolve, with developments in one reflected in the other (Barzelay, 2001).

In this paper, we explore this relationship between academia and policy with reference to landscapes, evaluating the extent to which landscape research has kept pace with developments in landscape policy. Landscape policy has evolved in recent years, from an approach that focused predominantly on the protection of nature, to one which is also sympathetic to, and inclusive of, social concerns. This progression is perhaps most evident in the European Landscape Convention (ELC), which was adopted in 2000 and came into force in 2004. Achieving such a shift in practice is, however, challenging, and policy-makers urgently need new tools, methods and guidance material, to enable them to develop and implement effective policies (De Montmollin, 2006). Academic research could undoubtedly contribute and arguably has a responsibility to do so, particularly when considering the various resource constraints which policy-makers face (Harvey, 2001; Thomas, 1999). However, landscape research and policy may be developing in diverging 
directions, with an emerging gap between the real-world concerns of policy-makers and the theoretical focus of academics (Hobbs, 1997) and with insufficient outreach and interaction between the two (Wu and Hobbs, 2002).

The main aim of this study is to determine whether landscape research has been keeping pace with recent policy developments. We first outline the evolution of landscape policy, and discuss four key innovations adopted in the ELC: (i) the inclusion of all landscapes (including lived-in landscapes) and landscape aspects, as foci of concern (scope), (ii) calls for participation of the public in processes relating to landscape protection, planning and management, (iii) the design of policies and measures tailored to different contexts and scales, and (iv) a focus on building capacity at local, regional and national levels. We then present the research questions related directly to these four aspects, and explain the methodology adopted for the review. Finally, we present and discuss the key results, and their implications for the future development of landscape research.

\section{Innovative directions in landscape policy}

The roots of landscape policy have much in common with traditional protectionist stances of nature conservation, with a predominant bias towards safeguarding outstanding areas of natural beauty (Everhart, 1972; Olwig and Olwig, 1979; Olwig, 2002; Stevens, 1997). However, key developments during the latter half of the 20th century contributed towards a gradual change in this perspective. Notable advances included the inscription of cultural landscapes on UNESCO's World Heritage List (Rössler, 1995, 2006), the inclusion of protected landscapes/ seascapes within the World Conservation Union's protected area categories (Phillips, 2005), and the set-up of the Pan-European Biological and Landscape Diversity Strategy (Council of Europe, 1996; Phillips, 1998). A growing awareness of the links between natural and cultural diversity (McNeely and Keeton, 1995) also contributed to an emerging perspective of landscapes as comprising both natural and human elements, and created through the interaction of the two.

One recent development in landscape policy has been the adoption of the European Landscape Convention (in 2000), a treaty which represents the culmination of this trend, away from an aristocratic conception of landscape to a democratic one (Olwig, 2002). It is the first international agreement to be exclusively concerned with all dimensions of European landscape. As of March 2011, it had been ratified by 33 Council of Europe States, with an additional five signatories. The ELC provides for the direct involvement of people in policy development and implementation, and for policy-makers to address issues of relevance to human societies (Council of Europe, 2000; Déjeant-Pons, 2006; Prieur, 2006). Four key innovations which are prominent in the convention, and which characterize this new stance are:

1. Scope: The ELC applies "to the entire territory of the Parties and covers natural, rural, urban and peri-urban areas. It includes land, inland water and marine areas. It concerns landscapes that might be considered outstanding as well as everyday or degraded landscapes" (Article 2). The basis for this expanded spatial focus, as noted in the ELC's Explanatory Report, is the fact that every landscape forms part of the setting for the lives of the population concerned, affects citizens' quality of life and deserves to be taken into account in landscape policies (Council of Europe, 2000). The expansion of scope is also substantive, in that the ELC seeks to foster a holistic approach to landscapes, considering both natural and human dimensions, and interlinkages between these. The explanatory report underlines this point stating "a landscape forms a whole, whose natural and cultural components are taken together, not separately" (Council of Europe, 2000).

2. Participation: The ELC establishes several requirements for public participation; indeed, its very definition of landscape as "an area, as perceived by people..." (Article 1) implies that the views of all groups should be included, not just the views of a political or academic elite (Jones, 2007). It further requires the establishment of "procedures for the participation of the general public" (Article 5c), the involvement of "interested parties and the population concerned" in identifying and assessing landscapes (Article 6c), and public consultation in the definition of landscape quality objectives (Article 6d). Prieur and Durousseau (2006) further specify that (i), the term 'public' should be taken to mean civil society in its broad sense, and (ii) the participation of the general public must be visible both in the definition and in the implementation of policy. The explanatory report explains the underlying rationale: "landscape is an issue which affects the whole population and care for the landscape requires collaboration between a wide range of individuals and organisations" (Council of Europe, 2000).

3. Contextual considerations: Whilst the geographical scope of the ELC is all-inclusive, the Explanatory Report specifies that measures and policies may differ across the range of European landscapes, adapted to the necessities of place. There is a deliberate emphasis on avoiding imposing any one policy model, with an understanding that specific contexts will dictate the appropriate forms of treatment. For the same reasons, the ELC talks of landscape protection, planning and/or management, providing a suite of options. Article $5 b$ of the ELC Convention also talks of "landscape policies" in the plural, reflecting not only diversity in geographical terms, but also the various levels of spatial responsibility, ranging from national authorities to local bodies.

4. Capacity-building: The Explanatory Report observes that landscape protection, management and planning can be complex matters necessitating multi-disciplinary work (Council of Europe, 2000). Article 6 of the ELC thus makes specific reference to the need for training and education, requiring, amongst other things, "training for specialists in landscape appraisal and operations", "multi-disciplinary training programmes", and "school and university courses". The ELC also makes indirect allusion to issues of human capacity in its references to the principle of subsidiarity and to the European Charter of Local SelfGovernment (Article 4), with the Explanatory Report specifying that where the competence for protection, management and planning of landscapes exists at local and regional levels, implementation will be most effective if carried out at these scales (Council of Europe, 2000). The ELC thus makes a case for building capacities at various levels across European countries.

Whilst there is little dispute concerning the ideological merits of these provisions, each aspect presents challenges for implementation. For example, whilst there is agreement that all landscapes merit attention, the field still lacks the technical, financial and legal means to appropriately address all landscape types and areas (Howard, 2004). Similarly, whilst landscape policy now establishes the notion of landscape being an area intimately tied to human perceptions and activities, a cursory review of much landscape literature suggests that the landscapes which have been most extensively studied are those least impacted by human activities and distant from the lived-in landscapes of many people (ibid). It would thus appear that landscape knowledge and technical capacities for landscape protection, planning and management are unevenly distributed across landscape types and 
geographical regions. De Montmollin (2006) also highlights difficulties in engaging the public in policy-making and implementation, noting major constraints because of the nature of existing planning instruments. Questions have also been raised about the challenges of involving people (Jones, 2007), such as who is entitled to participate, or whether there are landscapes that participation does not apply to. It is thus evident that whilst the principles of 'new' landscape policy as reflected in the ELC are highly laudable, implementation requires substantial further work, including appropriate supporting research.

This paper thus aims to determine whether academic landscape research has kept pace with changing landscape policy approaches. In this paper, we review the extent to which the four identified policy directions are reflected in academic landscape research, with the overall aim of assessing the strength of linkages between landscape research and policy. To do this, we ask four main questions:

1. Does the scope of landscape research reflect the holistic approach adopted in landscape policy?

2. What is the nature of public participation in landscape research?

3. Does landscape research take account of different contexts and scales?

4. Is there evidence that capacities to conduct landscape research are being enhanced?

We further address two overarching questions relating directly to the influence of the ELC on research agendas, namely:

5. To what extent has there been change in these four dimensions following adoption of the ELC in 2000?

6. Does European landscape research differ from research outside Europe?

\section{Methods}

\subsection{Approach}

The review approach adopted draws on methodological ideas presented in guidelines for producing systematic reviews from evidence-based conservation (Centre for Evidence-Based Conservation, 2010; Fazey et al., 2004, 2005; Pullin and Stewart, 2006). Such methods aim to increase rigour during the process of: (1) searching for appropriate studies; (2) deciding whether individual studies should be included in a review, and (3) integrating information from different studies (Centre for Evidence-Based Conservation, 2010). While this study is not a systematic review per se, elements of the systematic review process were adopted to improve replicability and reliability of results.

\subsection{Selection of studies for review}

Two different reviews were used to determine whether academic landscape research has kept pace with changing landscape policy approaches. These are:

A. A review of general landscape research, based on a sample comprising all research articles published in three leading landscape journals over two three-year periods (1995-97 and 2004-06);

B. A review of all research papers referring to the ELC in the title, abstract and/or keywords (spanning 2001 to June 2010).
Table 1

Distribution of general landscape research papers reviewed (breakdown by journals and year-groups).

\begin{tabular}{llccc}
\hline Journal & \multirow{2}{*}{$\begin{array}{l}\text { JCR Impact } \\
\text { factor }\end{array}$} & \multicolumn{2}{l}{ No. of papers } & \\
\cline { 3 - 5 } & & $1995-97$ & $2004-06$ & Total \\
\hline $\begin{array}{l}\text { Landscape ecology (LE) } \\
\begin{array}{l}\text { Landscape and urban } \\
\quad \text { planning (LUP) }\end{array}\end{array}$ & 2.45 & 89 & 226 & 315 \\
$\begin{array}{l}\text { Landscape research (LR) } \\
\text { Totals }\end{array}$ & 0.58 & 217 & 291 & 508 \\
& & 46 & 65 & 111 \\
& & 352 & 582 & 934 \\
\hline
\end{tabular}

\subsubsection{Review A - general landscape research}

Relevant landscape research could potentially be published in a range of journals; however, journals devoted explicitly to landscape are most likely to have a concentration of pertinent studies. For this reason, the sample comprised all research articles $(n=934)$ published in three leading landscape journals - Landscape Ecology (LE), Landscape and Urban Planning (LUP) and Landscape Research (LR) - during two three-year periods: 1995-1997 (prior to adoption of the ELC), and 2004-2006 (following adoption and initial stages of implementation). ${ }^{1}$ Editorials, commentaries and book reviews were excluded from the analysis. The three journals were selected on the basis of Journal Citation Reports (JCR) (Science Edition, 2008 and Social Sciences Edition, 2008) published by Thomson Reuters, being the only three journals included in the JCR database with landscape in the title (Table 1). As per stated aims and scope, the three journals reflect a range of concerns:

- Landscape Ecology focuses on the relationships between pattern and processes and their consequences, predominantly within ecological, nature conservation, environmental management, landscape planning, and landscape restoration domains.

- Landscape and Urban Planning is concerned with conceptual, scientific, and design approaches to land use, emphasizing in particular ecological understanding and a multi-disciplinary approach to analysis, planning and design.

- Landscape Research addresses a range of topics including design, management, ecology, geology, archaeology and cultural studies.

\subsubsection{Review B - ELC-related research}

The review included any journal papers referring to the European Landscape Convention in the title, abstract and/or keywords. A search for such papers was carried out using the ISI Web of Knowledge databases which cover close to 12,000 journals (Testa, Undated). The search returned 30 results, of which 27 were journal papers (with the remaining three being publications in conference proceedings), spanning a nine-year period (Table 2).

\subsection{Data collection and analysis}

The four main research questions outlined above were used as the basis for data collection. Specific sub-questions were derived

\footnotetext{
1 The full list of articles reviewed can be obtained from the contents lists of the three journals for the years concerned. These are available online, as follows: Landscape Ecology - http://www.springerlink.com/content/103025/; Landscape and Urban Planning - http://www.elsevier.com/wps/find/journaldescription.cws_home/ 503347/description\#description; Landscape Research - http://www.tandf.co.uk/
} journals/carfax/01426397.html. 
Table 2

Distribution of ELC-related papers reviewed (breakdown across journals and years).

\begin{tabular}{lcl}
\hline Journal & $\begin{array}{l}\text { No. of } \\
\text { papers }\end{array}$ & $\begin{array}{l}\text { Year of } \\
\text { publication }\end{array}$ \\
\hline $\begin{array}{l}\text { Biotechnologie agronomie société } \\
\quad \text { et environnement }\end{array}$ & 1 & 2009 \\
$\begin{array}{l}\text { Ekologia (Bratislava) } \\
\text { Environment and Planning B: }\end{array}$ & 2 & $2001 / 06$ \\
$\quad$ Planning and Design & 1 & 2008 \\
Environmental Geology & & \\
Land Use Policy & 1 & 2009 \\
Landscape and Urban Planning & 3 & $2009 / 10$ \\
Landscape Research & 3 & $2005 / 07 / 09$ \\
Norsk Geografisk Tidsskrift - Norwegian & 9 & $2006 / 07 / 08 / 09 / 10$ \\
$\quad$ Journal of Geography & 2 & 2007 \\
$\quad$ Ocean \& Coastal Management & & \\
Problemy Ekorozwoju & 1 & 2007 \\
Sociology - the Journal of the British & 1 & 2010 \\
$\quad$ Sociological Association & 1 & 2010 \\
$\quad$ Water and Environment Journal & 1 & 2007 \\
$\quad$ World Archaeology & 1 & 2009 \\
Total & 27 & \\
\hline
\end{tabular}

for each (Table 3), and review parameters defined (Table 4). Research question 5 (changes following adoption of the ELC) was addressed through comparisons between the two selected timeperiods. In order to address research question 6 (comparison of European/global research), research papers within review A which were authored by European institutions, were analysed as a separate subset. All research papers in review B were produced by European institutions, and such a subdivision was therefore not necessary. The review parameters were tested through a pilot review of 90 papers.

Whilst review questions were designed by all authors, all of the research papers (934 in review A and 27 in review B) were subsequently evaluated by the primary author, to ensure consistency. Descriptive statistics were used for analysis of all 961 papers; chisquared and Pearson-correlation tests of statistical significance were also used. The PASW Statistics 18.0 software package was used to facilitate data analysis.

\section{Table 3}

Sub-questions, relating to the four main research questions.

1. Does the scope of landscape research reflect the holistic approach of the ELC?

a. Which aspects of landscape are being studied?

b. Which disciplines are contributing to landscape research?

c. What types of landscapes are being studied?

\section{What is the nature of public participation in landscape research?}

a. To what extent is the public involved in the research process? b. What is the scope of public involvement in research?

c. What methods are used for involving the public?

3. Is landscape research adapted to different contexts?

a. Are study areas evenly distributed across Europe?

b. Is research representative of different spatial scales?

c. Is research representative of different temporal scales?

4. Is there evidence of enhancing capacities to conduct landscape research?

a. Is research capacity evenly distributed across Europe?

b. To what extent are local researchers involved in conducting

research in their own countries?

c. How much funding support is provided for landscape research?

\subsection{Limitations}

This review aims to provide a snapshot of landscape research at specific points in time rather than a complete review of all literature, and is based on ratings given by a single author. The sample is limited to three English language journals. However, given (i) the prominence of the English language in scientific publications and (ii) the high impact and relevance of the three journals reviewed, we argue that our study nevertheless provides a good indication of key trends in the field. Furthermore, whilst data extends only up to 2006, the publication periods selected for review were purposely intended to provide an indication of the uptake of policy directions, a few years after the adoption of the European Landscape Convention. We thus draw tentative conclusions on the basis of our findings.

\section{Results}

\subsection{Question 1: does the scope of landscape research reflect the} holistic approach adopted in landscape policy?

\subsubsection{Review A: general landscape research}

Landscape research appears to address a range of different landscape aspects. Approximately 33\% of papers reviewed are concerned exclusively with bio-physical landscape aspects (Fig. 1). These include studies of landscape structure, patterns and functions, specific floral and faunal species (including aspects such as productivity, behaviour and movements), and ecosystem/nutrient/sediment dynamics. $21 \%$ of papers are exclusively concerned with socio-cultural aspects (Fig. 1), addressing a variety of topics including human impacts on landscape, the implications of landscape issues for humans, human perceptions, and policy/management issues. The majority of papers reviewed (45\%) address both bio-physical and socio-cultural concerns; however, a significant decrease $\left(\chi^{2}=20.79, p=0.00\right)$ in such studies was observed between the two year groups. There is also a pattern to the distribution of papers across journals, with significant differences between these $\left(\chi^{2}=424.84, p=0.00\right)$. Each of the reviewed journals fills a specific niche within landscape research - Landscape Ecology leads the publication of studies on bio-physical aspects, Landscape Research leads the publication of studies on socio-cultural aspects, whilst Landscape and Urban Planning publishes most studies that deal with both. It would thus appear that whilst landscape research does cover a range of landscape aspects, research tends to be somewhat segmented.

Key disciplines contributing to academic landscape research are the life/physical sciences ( $42 \%$ of studies) and planning/management (33\% of studies) (Fig. 2). There are also lesser contributions from other social science disciplines, including sociology, economics, law, philosophy, anthropology, sociology, history and design. Overall there was a significant decline $\left(\chi^{2}=19.63, p=0.00\right)$ between the two year groups, in the proportion of multidisciplinary studies (60\% in 1995-97; 44\% in 2004-06). Contributing disciplines also vary depending on the journal. Landscape Ecology, for instance, mainly publishes research originating from the life/physical sciences. Landscape and Urban Planning has a broader span across natural and social science disciplines, whilst Landscape Research also includes contributions from disciplines which to date have been largely marginal to the field, such as philosophy and law.

The distribution of research across different landscape types is relatively even (Fig. 3), with minor (and statistically insignificant) changes over time. The types of landscapes studied also vary significantly between the different journals, with Landscape Ecology 
Table 4

Definition of review parameters.

\begin{tabular}{|c|c|c|}
\hline Objective & Criterion & Definition \\
\hline \multicolumn{3}{|l|}{ Scope } \\
\hline $1 \mathrm{a}$ & $\begin{array}{l}\text { Landscape aspects } \\
\text { under study }\end{array}$ & $\begin{array}{l}\text { Defined as the issues being addressed directly by the research. A distinction is made between topics of research } \\
\text { with a bio-physical focus and those with a socio-cultural focus. The former include physical and biological } \\
\text { properties of landscape and human impacts on physical landscapes whilst the latter include studies of implications } \\
\text { of landscape matters for humans, of human perceptions of landscape issues, together with studies relating } \\
\text { to planning and management of landscapes. Studies addressing topics with both physical and socio-cultural } \\
\text { topics were classified within a separate category. }\end{array}$ \\
\hline $1 b$ & Disciplines & $\begin{array}{l}\text { Defined as a set of paradigmatic structures, and shared philosophical and/or methodological approaches, } \\
\text { which give validity to the work produced within those structures. A distinction is made between disciplines } \\
\text { of the natural sciences (namely physics, biology, chemistry and mathematics) and those which are more social } \\
\text { science-oriented (namely anthropology, sociology, history, philosophy, law and economics). Design and planning } \\
\text { and management were also included in this latter category as they are concerned with anthropogenic elements and } \\
\text { with the control of anthropogenic activities. For purposes of this review, geography (both physical and human) } \\
\text { was considered to be intimately tied to the study of landscapes and was thus not considered as a distinct discipline. }\end{array}$ \\
\hline $1 \mathrm{c}$ & Landscape types & $\begin{array}{l}\text { Defined as: } \\
\text { 1. Natural areas (i.e. not directly modified for human purposes); } \\
\text { 2. Rural areas (i.e. countryside areas used primarily for production, e.g. through agriculture); } \\
\text { 3. Urban areas (i.e. towns and cities). }\end{array}$ \\
\hline
\end{tabular}

Participation

2a Extent of participation

2b Scope of participation

2c Methods of participation

Contextual considerations

3a Study areas

3b Spatial scales

3c Temporal scales

Capacity-building

$4 a \quad$ Location of institutions As in 3a above.

conducting research

$4 \mathrm{~b} \quad$ Local involvement

4c Funding

Defined as: conducted.
Expressed as the number of studies involving stakeholders.

4 categories were defined, based on two broad criteria, namely inclusivity (Kapoor, 2001; Nelson and Wright, 1995; Poolman and Van De Giesen, 2006; Slocum, 1995) and the nature of information flow (Health Canada, 2000; Kapoor, 2001; OECD, 2004; Pretty, 1995; Rowe and Frewer, 2004). Minimal participation involves stakeholders solely for the purpose of obtaining data that is otherwise unavailable/inaccessible, and/or for testing data or methodologies. Minor participation considers stakeholders' views, concerns and knowledge. However, stakeholders are limited to the research community, academics, professionals and official agencies. Moderate participation incorporates the views, concerns, and knowledge of a wide range of stakeholders, including the general public. High participation goes beyond the extractive process of eliciting views and actively seeks to facilitate and empower stakeholders and/or to build capacity for stakeholders to undertake analysis and management.

Methods identified from the review were questionnaires, interviews, group methods (i.e. focus groups, group meetings and workshops), Participatory Rural Appraisal (PRA) methods (Chambers, 1994) and Visitor Employed Photography (VEP) (Oku and Fukamachi, 2006; Stedman et al., 2004).

Study areas were classified on the basis of the countries within which they are located, with specific reference to Council of Europe member states, and to their status with respect to signature/ratification of the ELC. Countries were also analysed on an international basis as per the World Bank List of Economies (The World Bank, 2010). In the latter case, economic categories are based on Gross National Income (GNI) per capita, as follows: low income, i.e. $\leq \$ 975$ (e.g. Kenya, India), lower-middle income, i.e. \$976-\$3855 (e.g. Brazil, Philippines), upper-middle income, i.e. \$3856-\$11,905 (e.g. Russian Federation, Turkey), and high income, i.e. $\geq \$ 11,906$ (e.g. USA, Germany).

1) Local (circa $\left.<1-100 \mathrm{~km}^{2}\right)$;

2) Micro-regional (circa 100 to $1000 \mathrm{~km}^{2}$ );

3) Meso-regional (circa $1000-10^{8} \mathrm{~km}^{2}$ );

4) Global $\left(>10^{8} \mathrm{~km}^{2}\right)$

Classified as:

1) Short-term (1-10 years);

2) Short to medium-term (11-50 years);

3) Medium to long-term (51-100 years);

4) Long-term ( $>100$ years).

Defined on the basis of whether any of the authors represent an institution from the country where the study is being

Studies which were externally funded were identified on the basis of listed acknowledgements.

focusing predominantly on natural and rural areas, and Landscape and Urban Planning and Landscape Research addressing urban areas to a larger degree.

\subsubsection{Subset of European research}

Whilst the description above includes all research reviewed (including non-European studies), research published by European institutions largely replicates the same patterns of focus, and distribution across time and in different journals. It is of interest to note, however, that of the only four studies dealing with landscape law, three were written within a European context in the 2004-06 period (thus after adoption of the ELC).

\subsubsection{Review B: ELC-related research}

ELC-related research is oriented mainly towards social science landscape aspects. 26 of the 27 ELC studies reviewed address a socio-cultural topic, mostly landscape planning and management. Other areas of focus include environmental psychology and cultural identity. Key disciplines contributing to research are planning/ management (78\% of studies), with lesser contributions from history (22\%), law (4\%) and sociology (11\%). Many studies do not deal with specific landscape types but rather with general concepts. Of those that do address specific landscape types, 6 studies (22\%) deal with rural landscapes, 2 (7\%) with natural landscapes and 3 (11\%) with predominantly urban landscape features. 


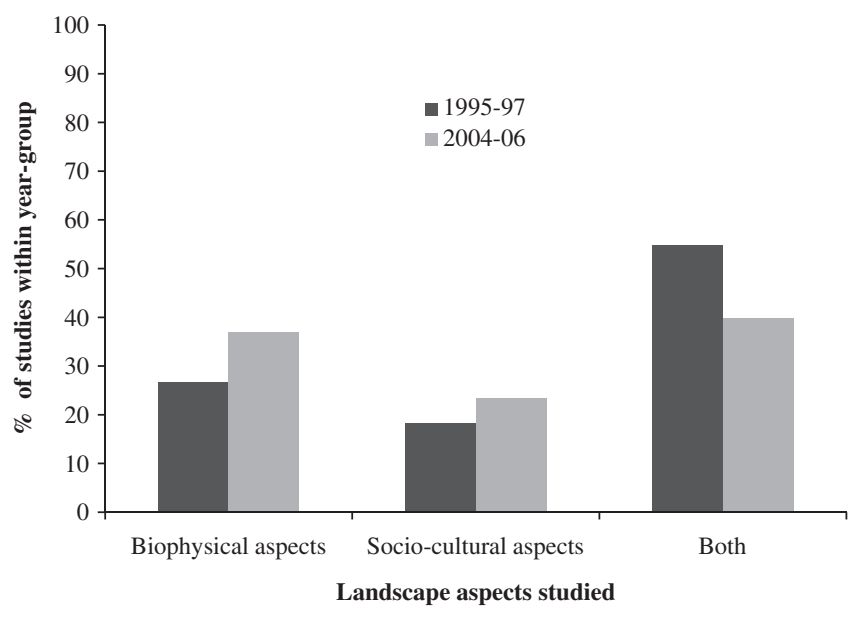

Fig. 1. Differences in landscape aspects addressed by research, between 1995-97 $(n=352)$ and 2004-06 $(n=582)$.

\subsection{Question 2: what is the nature of public participation in landscape research?}

\subsubsection{Review A: general landscape research}

The extent of public involvement in research is very limited. $84 \%$ of studies reviewed did not engage with any stakeholders. Although there was a slight increase in stakeholder involvement, (14\% in $1995-97 / 17 \%$ in $2004-06$ ), this is not statistically significant $\left(\chi^{2}=0.63, p=0.43\right)$. Stakeholder groups involved in research include both those likely to represent public interests (e.g. NGOs, locals/resource users), as well as others representing a specific governmental and/or scientific agenda (e.g. official agencies, research community).

The scope of public involvement is largely moderate (Table 4 and Fig. 4), i.e. incorporating the views and knowledge of a wide range

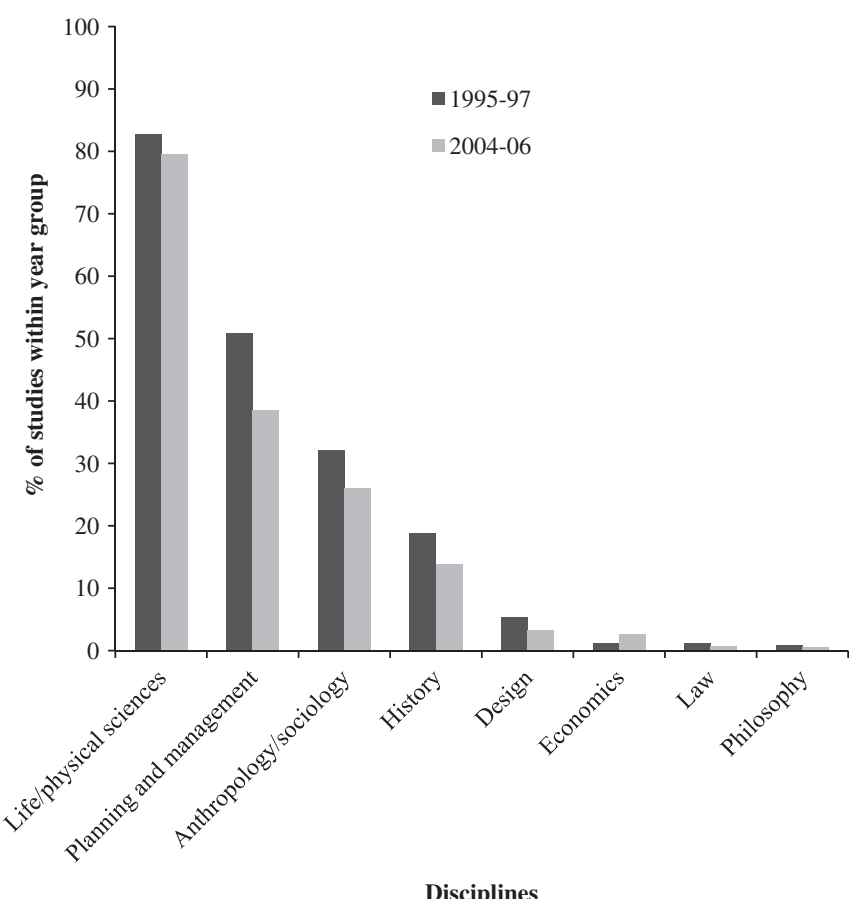

Fig. 2. Differences in the contribution of different disciplines to landscape research, between 1995-97 $(n=352)$ and 2004-06 $(n=582)$.

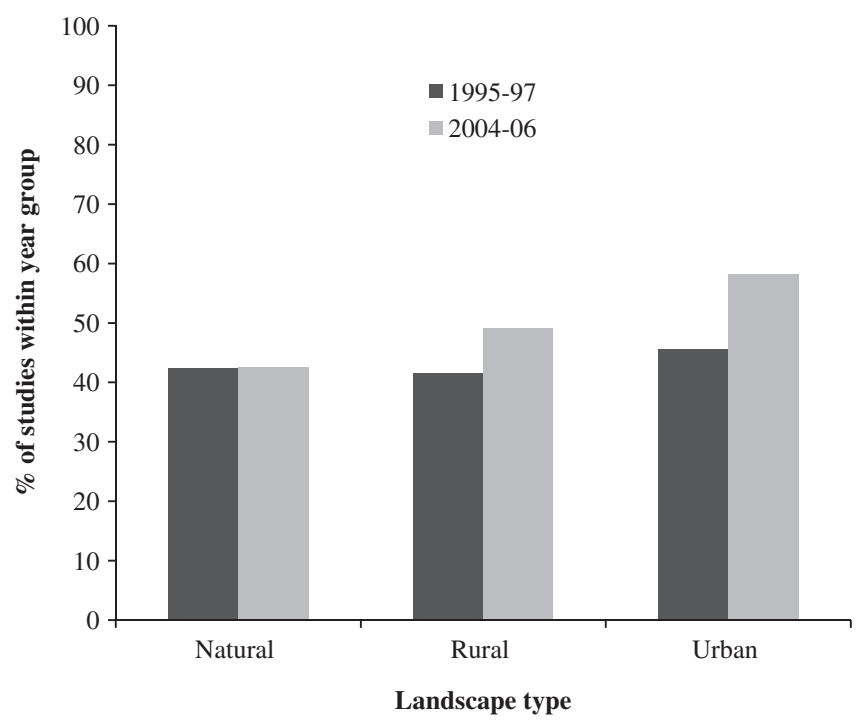

Fig. 3. Differences in landscape types studied, between 1995-97 $(n=352)$ and 2004-06 $(n=582)$.

of people. There has been a decline in the percentage of studies involving stakeholders either for eliciting and/or testing data (minimal participation), and in those studies where stakeholder involvement is limited to professionals, academics and/or official agencies (minor participation). Nevertheless, the percentage of studies which may be considered truly participatory (high participation) remains limited. Significant changes have occurred in the relative proportion of different stakeholder involvement classes over the time-span of this review $\left(\chi^{2}=12.1, p<0.05\right)$.

The extent to which studies involve stakeholders is significantly correlated to the topic of study (Pearson-correlation $=0.133$, $p<0.00$ ) (Fig. 1); indeed, participation is lowest amongst studies published in Landscape Ecology (2\% of studies involve stakeholders), which as discussed, tend to predominantly address bio-physical concerns. Conversely, $27 \%$ and $23 \%$ of papers published in Landscape Research and Landscape and Urban Planning respectively involve some element of participation.

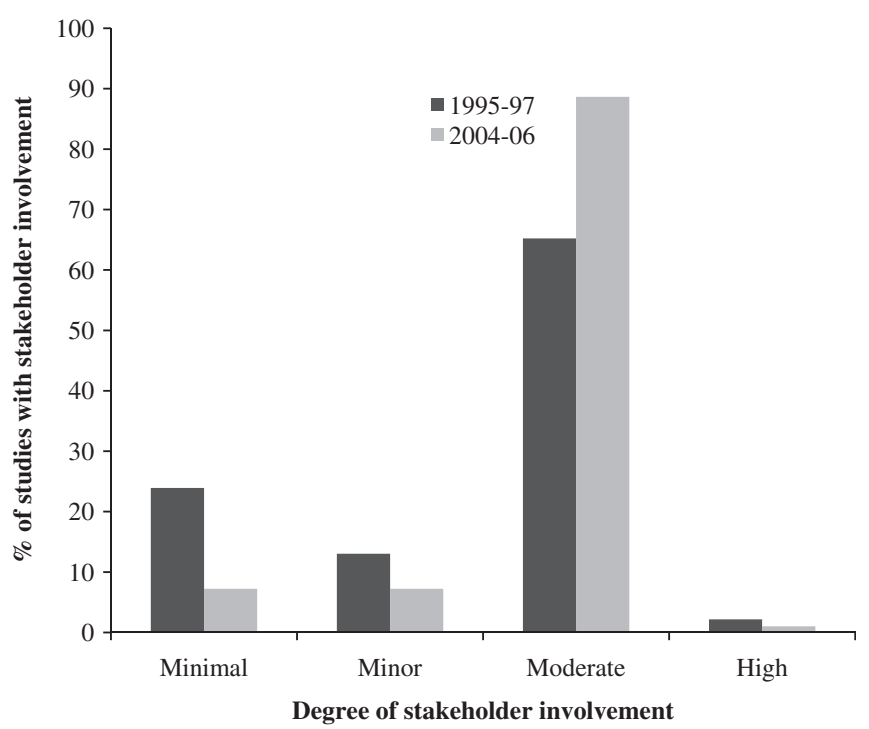

Fig. 4. Differences in the scope of stakeholder involvement, between 1995-97 $(n=352)$ and 2004-06 $(n=582)$. 


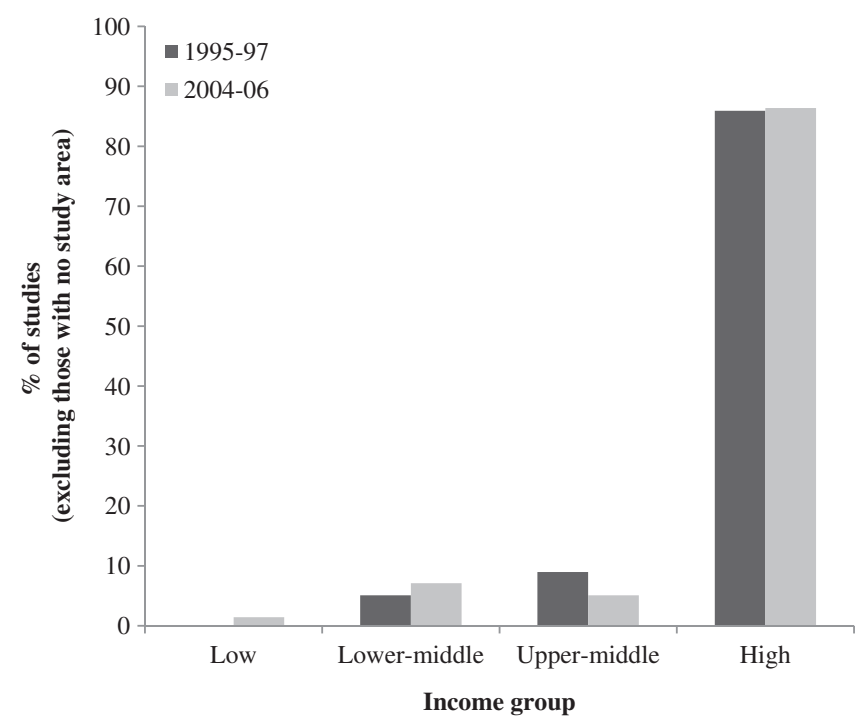

Fig. 5. Differences in the distribution of research sites (categorized by the income group of countries) between 1995-97 $(n=352)$ and 2004-06 $(n=582)$.

The dominant methods used to involve the public are interviews and questionnaires, used in $63 \%$ and $42 \%$ of participatory studies respectively. Whilst there have been changes between the two year-groups in the methods used (e.g. increased use of group methods such as focus groups and workshops, and increased use of innovative techniques, such as Visitor Employed Photography), changes were not found to be statistically significant $\left(\chi^{2}=9.3\right.$, $p>0.05$ ). The use of techniques other than interviews and questionnaires remains largely marginal.

\subsubsection{Subset of European research}

The extent and nature of stakeholder involvement in European research is similar to that of the overall sample of research studies, with $83 \%$ of studies without stakeholder involvement, and with stakeholder involvement tending to be of moderate degree, implemented primarily through interviews and questionnaires.

\subsubsection{Review B: ELC-related research}

The extent of public involvement in ELC-related research is also limited. 4 of the 27 ELC studies reviewed (15\%) involved stakeholders in the research process. In all cases, the scope of public involvement was to elicit public opinions on an issue of interest, ranging from visual landscape preferences to landscape aspirations. 3 of the 4 studies consulted members of the general public (moderate

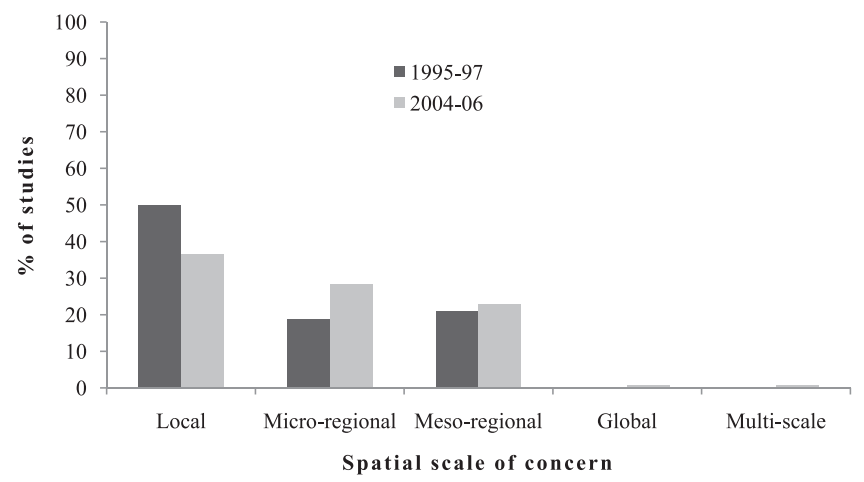

Fig. 6. Differences in the spatial scale of concern addressed by research, between 1995-97 $(n=352)$ and 2004-06 $(n=582)$. participation); one of these focused specifically on the local community of place. The fourth study consulted representatives of official agencies (minor participation). Methods used to involve the public included postal questionnaires (1 study), an Internet survey ( 1 study), focus groups ( 1 study) and interviews ( 2 studies).

\subsection{Question 3: does landscape research take account of different contexts and scales?}

\subsubsection{Review A: general landscape research}

$19 \%$ of papers published are based on general concepts, without specific study-sites. Amongst those papers which do focus on specific areas, there is an uneven geographical distribution of studysites. Most research is conducted in the USA (34\%), followed by the UK (8\%), Canada (6\%), Australia and China (4\%), and France, Spain and Germany (3\%). Overall, $86 \%$ of research was conducted in highincome countries (Fig. 5).

Studies reviewed represent a range of spatial scales (Fig. 6). $42 \%$ of studies address a local remit, 25\% deal with micro-regional scales, $22 \%$ address meso-regional areas and $0.4 \%$ focus on global concerns. $11 \%$ of studies did not deal with a specific spatial scale. In relation to temporal scales, most research (54\%) addressed a shortterm time-frame (Fig. 7). Several studies did not address a specified time-frame (27\%). There are significant differences between the two year-groups for both spatial $\left(\chi^{2}=23.5, p=0.001\right)$ and temporal $\left(\chi^{2}=18.2, p=0.005\right)$ scales.

\subsubsection{Subset of European research}

European countries of study included 28 of the 47 Council of Europe member states (Fig. 8). Notable gaps include several countries in Eastern Europe, as well as many of the smaller European states. The range of spatial and temporal contexts covered by European landscape research is broadly similar to that of the general sample.

\subsubsection{Review B: ELC-related research}

A considerable proportion (56\%) of reviewed ELC papers addressed broad conceptual issues rather than specific study areas. The geographical distribution of study-sites in the fifteen studies that included study areas spanned ten states; nine of these lie in northern/central Europe. The spatial scale of concern is mostly meso-regional (44\%), often pan-European. A slightly lower proportion of studies (41\%) focus on the micro-regional level, whilst 3 studies (11\%) address local concerns, and 1 (4\%) addresses

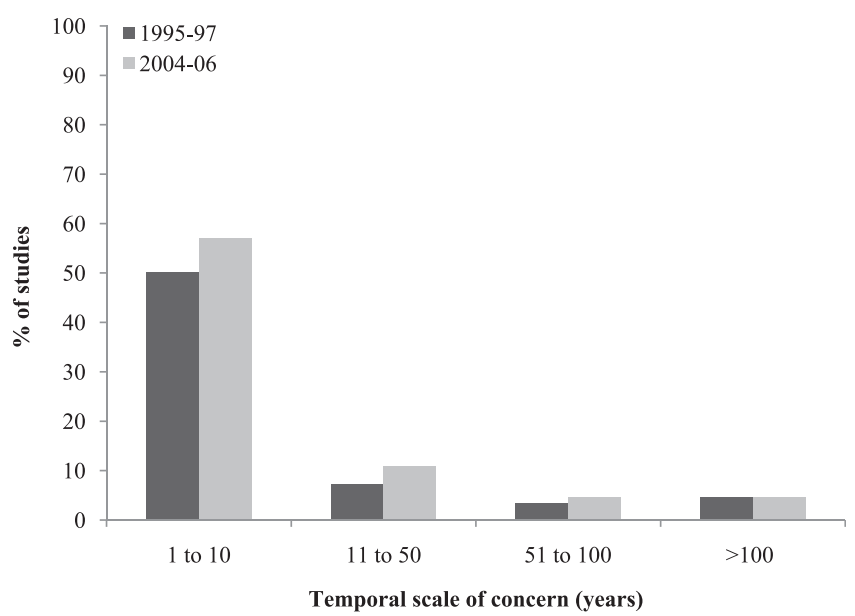

Fig. 7. Differences in the spatial scale of concern addressed by research, between 1995-97 $(n=352)$ and 2004-06 $(n=582)$. 


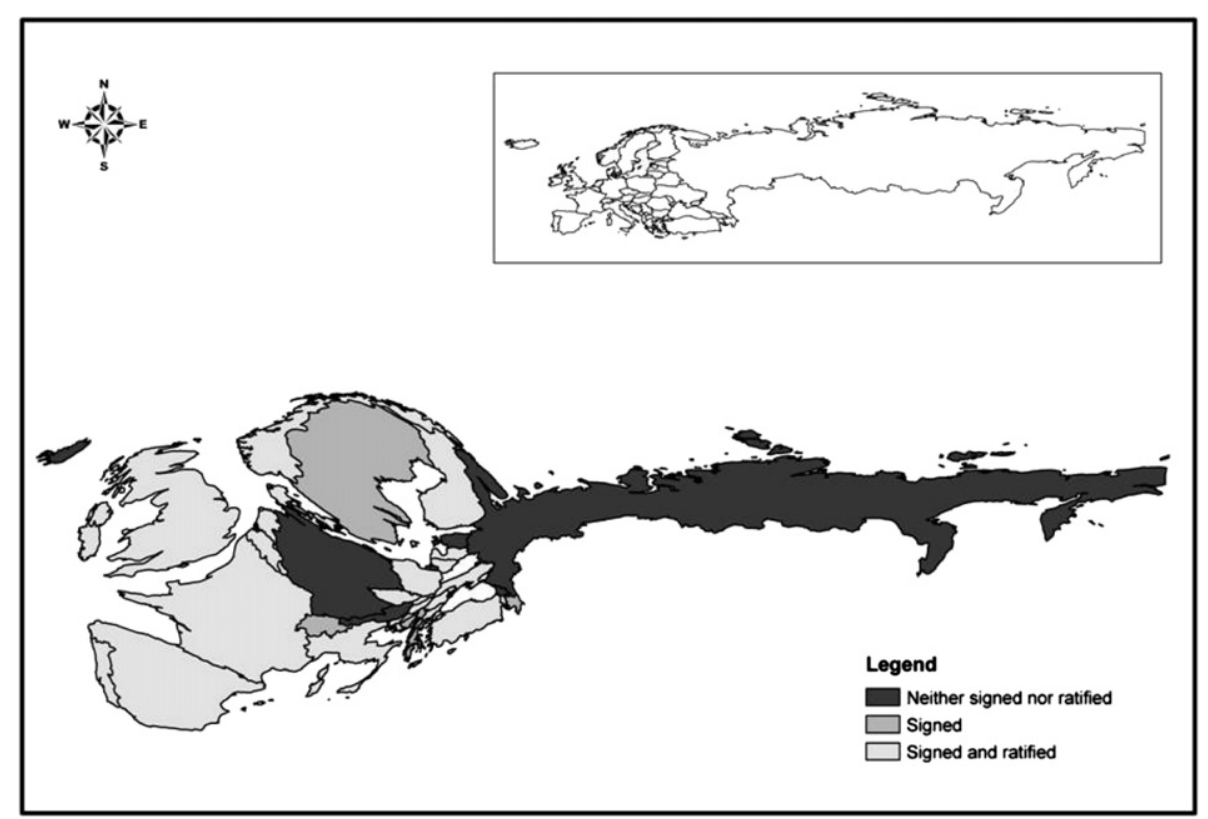

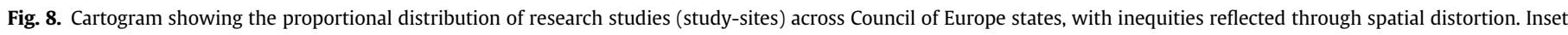
shows the same map, without distortion. The legend indicates the status of the various states in relation to the ELC.

a global spatial scale. In terms of temporal scales, the majority of studies (74\%) have a short-term focus, but some (26\%) also take into consideration the historical dimensions of landscape.

\subsection{Question 4: is there evidence that capacities to conduct landscape research are being enhanced?}

\subsubsection{Review A: general landscape research}

The geographical distribution of research capacity is very uneven. Most landscape research originates from institutions in the United States (36.4\%), followed by the UK (10\%), Canada (7\%) and the Netherlands and Australia (5\%). 92\% of research was conducted by institutions in high-income countries - research in upper-middle income (4.2\%), lower-middle income (2.8\%) and low income $(0.6 \%)$ countries comprised a minor portion of the sample (Fig. 9). 95\% of research involving areas of study in high-income countries included researchers from those countries, but in upper-middle income, lower-middle income and low income countries, this proportion constituted $75 \%, 63 \%$ and $71 \%$ respectively. Results suggest that research tends to be more extractive in nature when countries of study are poorer.

Funding support for landscape research appears to be moderate. $54 \%$ of studies acknowledge financial support, with these increasing from $42 \%$ in $1995-97$ to $60 \%$ in $2004-06$. There is evidence of a correlation between the topics of research and the extent of funding support (Pearson-correlation $=-0.189, p<0.00$ ), as well as a significant difference between the extent of funding allocated and different types of research topics $\left(\chi^{2}=67.9, p<0.00\right)$. $72 \%$ of studies addressing bio-physical concerns received funding, as compared to $37 \%$ of studies dealing with socio-cultural aspects, and $48 \%$ of studies dealing with both. Similarly, $58 \%$ of studies relating to natural and physical science disciplines received funding support.

\subsubsection{Subset of European research}

$40 \%$ of research reviewed includes an author from a European institution. The main contributing country is the UK $(26 \%$ of
European studies), and there is also considerable research input from the Netherlands (12\%), Spain, France and Germany (9\%), and Sweden (8\%). However, it would appear that there is unequal research capacity across Europe, with European countries represented constituting only 24 of the 47 Council of Europe member states (Fig. 10). 33 states have ratified the ELC to date; published research originated from institutions in 17 of these. Additionally, five countries have signed but not ratified the ELC; of these, three are represented within the research analysed. Several of the countries not represented lie within Eastern Europe, with some additional 'gaps' in Central and Southern Europe. 94\% of studies in European countries involved an author from the country of study.

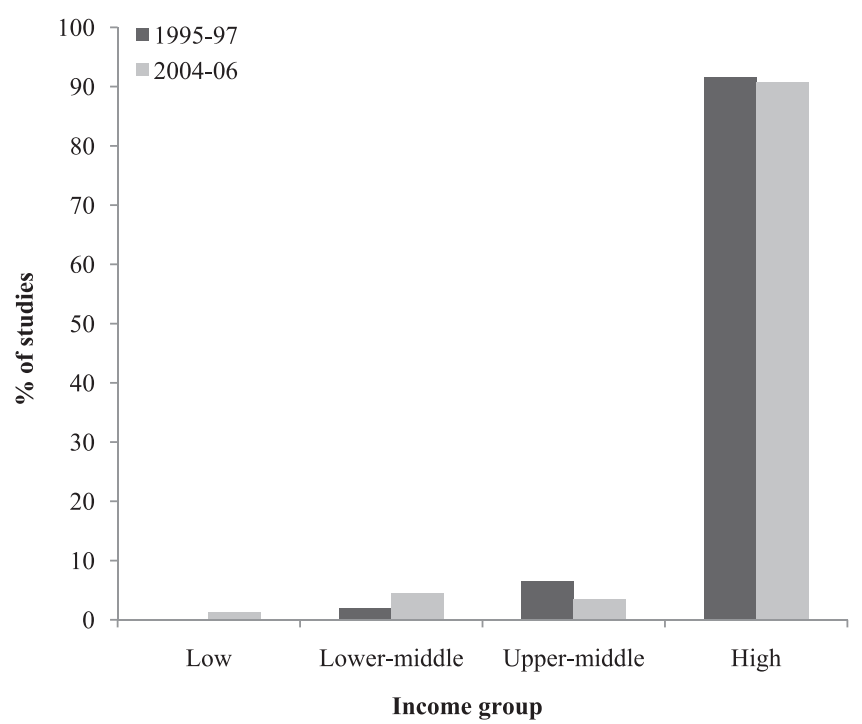

Fig. 9. Differences in the distribution of research institutions across country income categories, between 1995-97 $(n=352)$ and 2004-06 $(n=582)$. 


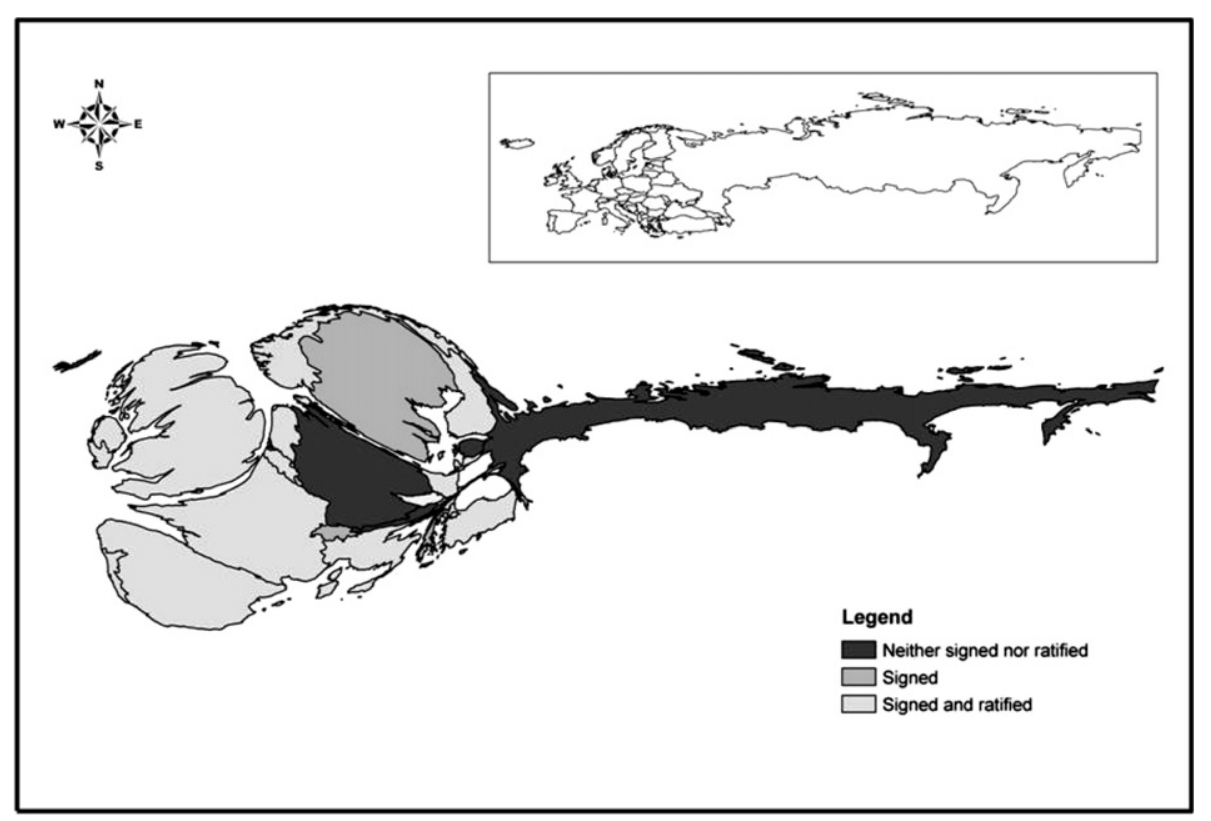

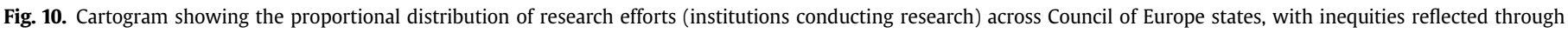
spatial distortion. Inset shows the same map, without distortion. The legend indicates the status of the various states in relation to the ELC.

Overall, $48 \%$ of European studies received external funding, increasing from $36 \%$ to $55 \%$ over the time-span of the review. There is a similar correlation within European research, between the provision of funding and the scope of research, with a bias towards funding for work in the life and physical sciences. The top European countries for funding support are Spain (with $72 \%$ of studies receiving funding support), Germany (68\%), France (65\%), Switzerland (64\%) and Estonia (55\%). Funding agencies include various ministries (of environment, agriculture, spatial planning, research, education and/or science), together with research organisations, conservation agencies, and other foundations. A number of studies also acknowledge funding support from European Commission and European Union initiatives.

\subsubsection{Review B: ELC-related research}

The geographical distribution of research capacity appears to be skewed towards Northern European countries, notably the UK (22\%), Sweden (19\%) and Norway and Belgium (15\%). The 27 papers published included authors from 13 European states, of which 11 have ratified the ELC. Of the remaining two, Sweden has signed but not ratified the convention, whilst Germany has not signed the convention. The degree of involvement of local researchers is very high, with all of the 15 studies which involve a specific study area including a researcher from the same country of study. 33\% of studies $(n=9)$ were provided with funding support, with the majority of these in the UK (4 studies), followed by Sweden ( 2 studies) and Norway, Czech Republic, and Ireland (1 study each).

\section{Discussion: linkages between landscape research and policy}

The results provide an indication of the state of the research-praxis interface, i.e. the extent to which research is keeping pace with developments in landscape policy (Table 5).

\subsection{Scope}

Results indicate that overall, landscape research is reflective of the scope of landscape policy, both in terms of (i) the range of landscape aspects being studied, and (ii) the types of landscapes being studied. The balance is not achieved through any single journal, but rather through the spectrum of research presented in different landscape journals. There is nevertheless scope to better address landscapes which to date have not been well-studied, such as freshwater environments, seascapes and peri-urban areas. Furthermore, it is of concern that research appears to be increasingly reductionist, in contrast to the ELC's stand that landscape is holistic, and that natural and cultural components should be addressed together, not separately (Council of Europe, 2000). Results also suggest potential for better integration of research in different subject areas and for a more significant input from disciplines which have so far made only marginal contributions. For example, given that implementation of the ELC faces large legal and financial challenges (Howard, 2004), more extensive legal and economic research could potentially be of benefit.

Table 5

The state of landscape research: summary.

\begin{tabular}{ll}
\hline Positive aspects & Negative aspects \\
\hline Range of landscape aspects being studied & Little research directly addressing landscape policy \\
Contributions from various disciplines & Low direct influence of policy on research \\
Different landscape types being studied & Decline in multi-disciplinary research \\
Moderate funding support & Segregation of research topics in specialized journals \\
Range of spatial scales being studied & Limited public involvement in research \\
Involvement of local researchers (within Europe) & Lack of research on participatory concepts/techniques \\
& Lack of research on long-term landscape evolution \\
& Uneven geographical distribution of study areas \\
& Uneven geographical distribution of research capacities \\
\hline
\end{tabular}




\subsection{Public participation}

Results suggest that the participatory emphasis of landscape policy is not being given equal priority in landscape research, which remains, to a large extent, the sole domain of scientific 'experts'. The extent of participation is limited overall, as also in terms of the types of studies which seek stakeholder involvement. Given that the ELC calls for extensive public involvement, in assessing landscapes, in identifying their characteristics, and in defining quality objectives (all of which are also in part addressed by academic research), there is significant scope for academia to develop closer ties to the public in contributing to landscape strategies. There is also scope for more research innovation in terms of developing new participatory techniques for landscape protection, planning and management, given an identified need for such new instruments (De Montmollin, 2006; Glover et al., 2008).

\subsection{Context and scale}

There appears to be reasonable representation of spatial scales, even if landscape change at the global level has received less attention, but short-term concerns dominate the temporal focus. Results also highlight inequities in the distribution of studied landscapes across Europe and on a global scale. At European level, the areas where least research appears to have been carried out are also ones which face formidable context-specific challenges in protecting, planning and managing landscapes. Taking Eastern Europe as an example, the transition from the former USSR to politically independent states has brought with it significant landscape change, reflecting aspects of local culture as well as the less welcome influence of a foreign occupying power, and thus raising difficult questions for landscape conservation and management (Bell et al., 2009). Similarly, small European states face a unique difficulty in accommodating a multitude of demands on land use within a very limited land area (Steinmetz and Wivel, 2010), as do small islands rendered vulnerable by insularity (Briguglio, 1995; Encontre, 1999). Thus, there is a need for the geographical representativeness of research to be given more consideration.

\subsection{Capacity-building}

The ELC's focus on local capacity and its implicit support of local knowledge appears to discourage extractive research being conducted by outsiders without the involvement of local institutions. This does not appear to be a concern for Europe, since most studies involve local researchers, but there is an evident dearth of research capacity in many non-European countries. Even within Europe, whilst substantial capacity already exists in Northern, Western and Central Europe, implementation of landscape policy in other areas will require concerted efforts for building capacity. Furthermore, if landscape studies are to support policy priorities, then funding may need to be directed accordingly, and provided for specific study topics which address existing research gaps.

\subsection{Overall influence of the ELC}

Landscape policy does not appear to be a major stimulus for academic research at present, even though it establishes many challenges which academics could productively take up. There appears to be little direct influence of the ELC on European research, given that patterns and trends in Europe replicate those occurring on a worldwide basis. Observed changes over time likewise do not appear to be linked to the policy directions established in the ELC. This does suggest that the two 'worlds' are evolving in isolation from each other, and there is thus significant scope for developing stronger collaborations between the two.

\section{Conclusions: implications for the future of landscape research}

The review provides a broad overview of key trends in landscape research, in relation to four policy innovations. Overall, results provide cause for both optimism and concern (Table 5). There is evidence of a breadth and diversity of landscape research, which though not directly addressing landscape policy, could certainly contribute to its successful implementation. However, there appears to be a bias in academia towards ecological concerns, which contrast with the more holistic approach adopted in landscape policy. This is not to downplay the significance of landscape ecology or of bio-physical research aspects, which remain highly pertinent fields of study. However, these arguably need to be better linked to their policy implications. Jones et al. (2007) in fact note that one of the most important contributions of landscape ecologists for the implementation of the ELC may be to develop models and tools to facilitate communication between and among planners, decision-makers and stakeholders that promote a sustainable development of landscapes.

Indeed, while we have discussed this review in terms of policy needs, the discussion can also be framed around the policy relevance of research. In his seminal review of landscape ecology, Hobbs (1997) noted that "landscape ecology is uniquely poised to play a major role in tackling today's major conservation and land-use issues and in developing responses to the pressing problems arising as a result of human-induced global change" (p. 1), and highlights the urgency of these practical concerns. However, he goes on to note that although in theory, landscape ecology is an applied science, the extent to which it actually is applied is "very little" (p. 5), with limitations including little cross-fertilization across disciplines, the lack of accessibility/comprehendability of landscape ecological research to those outside the field, and the orientation of much research towards theoretical rather than practical implementation. More than twelve years on, this research suggests that these concerns are still relevant, with different journals pursuing their own 'niche' of concern and with relatively little multi-disciplinary, interdisciplinary and transdisciplinary work, limiting the ability of such work to account for real-world complexity (Tress et al., 2001). Researchers are effectively 'preaching to the converted', and mostly to those who speak their own language. Landscape and Urban Planning is arguably the exception in presenting and integrating research on a variety of aspects within one journal.

The geography of research also emerges as a point of concern. Whilst the research-wealth relationship (Das et al., 2010) is perhaps not surprising, the dominance of specific (e.g. US/UK) geographical perspectives can greatly limit the applicability of research to other policy contexts. This has already been documented with reference to, for example, economic policies; the Commision on Growth and Development (2008) notes that "orthodoxies apply only so far", and Das et al. (2010) extrapolate that if policies need to be country-specific, we clearly need a body of work on a country before we can start talking of policy. We argue that the same applies to landscape policies; whilst research can provide useful general insights, it also needs to provide context-specific insights which would help render policy more applicable, effective and rigorous. Geography also perhaps constitutes one of the limitations of the ELC; whilst its European remit makes administrative sense, limiting the scope of concern to Europe can be difficult in an era of multi-faceted globalization 
(Zimmerer, 2006). Mediterranean Europe, for example, is heavily shaped not only by interactions with northern European neighbours but also by biogeographical, social and economic flows across the Mediterranean Basin to the North African shore (Lutterbeck, 2006; Ribas-Mateos, 2005). Perhaps in due course the ELC should be expanded to an international level, given that landscape change is also a product of global change (Baker, 1989; Lavorel et al., 1998; Thompson et al., 1998); indeed, proposals for a Global Landscape Convention have already been put forward (Ibrahim, 2010).

This review thus provides an indication of specific gaps in landscape research which could be productively addressed. There is potential for landscape to become a matter of more concern to more disciplines, including, for example, environmental and ecological economics, architecture, design, energy sciences, law, history, psychology and sociology. Given, however, that in practice, landscape issues are never the sole preserve of a single discipline, research effectiveness may be best enhanced through interdisciplinary and transdisciplinary approaches, the latter fostering crucial linkages with society at large.

\section{References}

Alison, L., West, A., Goodwill, A., 2004. The academic and the practitioner: pragmatists' views of offender profiling. Psychol. Public Pol L 10 (1/2), 71-101.

Baker, W.L., 1989. A review of models of landscape change. Landscape Ecol. 2 (2), 111-133.

Barzelay, M., 2001. The New Public Management: Improving Research and Policy Dialogue. University of California Press, Berkeley.

Bell, S., Nikodemus, O., Peneze, Z., Kruze, I., 2009. Management of cultural landscapes: what does this mean in the former Soviet Union? A case study from Latvia. Landscape Res. 34 (4), 425-455.

Briguglio, L., 1995. Small island developing states and their economic vulnerabilities. World Dev. 23 (9), 1615-1632.

Centre for Evidence-Based Conservation, 2010. Guidelines for Systematic Review in Environmental Management, Version 4.0. Available at. Collaboration for Environmental Evidence, Bangor. http://www.environmentalevidence.org/ Documents/Guidelines.pdf Last accessed June 2010.

Chambers, R., 1994. Participatory rural appraisal (PRA): challenges, potentials and paradigm. World Dev. 22 (10), 1437-1454.

Commision on Growth and Development, 2008. The Growth Report: Strategies for Sustained Growth and Inclusive Development. The International Bank for Reconstruction and Development/The World Bank, Washington DC.

Council of Europe, 1996. Pan-European Biological and Landscape Diversity Strategy. Available at. Council of Europe Press, Strasbourg. http://www.peblds.org/ Last accessed July 2010.

Council of Europe, 2000. European Landscape Convention. Available at. http:/ conventions.coe.int/Treaty/en/Treaties/Html/176.htm Last accessed July 2010.

Curtis, M., 2004. Britain's real foreign policy and the failure of British academia. Int. Relations 18 (3), 275-287.

Das, J., Do, Q.T., Shaines, K., Srinivasan, S., 2010. U.S. and Them: The Geography of Academic Research. World Bank Policy Research Working. Paper No. 5152.

Déjeant-Pons, M., 2006. The European landscape convention. Landscape Res. 31 (4), $363-384$.

De Montmollin, B., Council of Europe, 2006. Landscape and innovative tools. In: Landscape and Sustainable Development: Challenges of the European Landscape Convention. Council of Europe Publishing, Strasbourg, pp. 83-96.

Encontre, P., 1999. The vulnerability and resilience of small island developing states in the context of globalization. Nat. Resour. Forum 23 (3), 261-270.

Everhart, W.C. 1972. The National Park Service. Praeger Publishers, New York

Fazey, I., Salisbury, J.G., Lindenmayer, D.B., Maindonald, J., Douglas, R., 2004. Can methods applied in medicine be used to summarize and disseminate conservation research? Environ. Conserv, 31 (3), 190-198.

Fazey, I., Fischer, J., Lindenmayer, D.B., 2005. Who does all the research in conservation biology? Biodivers. Conserv. 14, 917-934.

George, A.L., 1994. The 2 cultures of academia and policy-making - bridging the gap. Polit. Psychol 15 (1), 143-172.

Glover, T.D., Stewart, W.P., Gladdys, K., 2008. Social ethics of landscape change: toward community-based land-use planning. Qual. Inq. 14 (3), 384-401.

Haggerty, K.D., 2004. Displaced expertise: three constraints on the policy-relevance of criminological thought. Theor. Criminol. 8, 211-231.

Harvey, D.R., 2001. Academic rigour or policy relevance: towards a reconciliation. In: Peters, G.H., Pingali, P. (Eds.), Tomorrow's Agriculture: Incentives, Instituinfrastructure and Innovations. Ashgate Publishing, Aldershot, pp. $565-582$.
Health Canada, 2000. Health Canada Policy Toolkit for Public Involvement in Decision Making. Corporate Consultation Secretariat, Health Policy and Communications Branch.

Hobbs, R., 1997. Future landscapes and the future of landscape ecology. Landscape Urban Plan. 37 (1-2), 1-9.

Howard, P., 2004. Spatial planning for landscape: mapping the pitfalls. Landscape Res. 29 (4), 423-434.

Hughes, T., O'Regan, N., Wornham, D., 2008. The credibility issue: closing the academic/practitioner gap. Strategic Change 17 (7-8), 215-233.

Ibrahim, M., 2010. Landscape architects argue case for global landscape convention. In: Horticulture Week, 30th April 2010.

Jones, M., 2007. The European Landscape Convention and the question of public participation. Landscape Res. 32 (5), 613-633.

Jones, M., Howard, P., Olwig, K.R., Primdahl, J., Herlin, I.S., 2007. Multiple interfaces of the European landscape convention. Norsk Geogr. Tidsskr 61 (4), 207-215.

Kapoor, I., 2001. Towards participatory environmental management? J. Environ. Manage. 63 (3), 269-279.

Lavorel, S., Canadell, J., Rambal, S., Terradas, J., 1998. Mediterranean terrestrial ecosystems: research priorities on global change effects. Glob. Ecol. Biogeogr 7 (3), 157-166.

Lutterbeck, D., 2006. Policing migration in the Mediterranean. Mediterr. Polit. 11 (1), 59-82.

McNeely, J., Keeton, W.S., 1995. The interaction between biological and cultural diversity. In: Droste, V.B., Plachter, H., Rössler, M. (Eds.), Cultural Landscapes of Universal Value. Gustav Fischer, Stuttgart, pp. 25-37.

Moats, J.B., McLean, G.N., 2009. Speaking our language: the essential role of scholarpractitioners in HRD. Adv. Dev. Hum. Resour., 507-522.

Nelson, N., Wright, S., 1995. Power and Participatory Development. Intermediate Technology Publications, London.

Nye Jr., J.S., 2008. Bridging the gap between theory and policy. Polit. Psychol. 29 (4), 593-603.

OECD, 2004. Stakeholder Involvement Techniques. OECD, Paris.

Oku, H., Fukamachi, K., 2006. The differences in scenic perception of forest visitors through their attributes and recreational activity. Landscape Urban Plan. 75 $(1-2), 34-42$

Olwig, K., Olwig, K., 1979. Underdevelopment and the development of "natural" park ideology. Antipode 4 (1), 16-25.

Olwig, K.R., 2002. Landscape, Nature and the Body Politic: From Britain's Renaissance to America's New World. The University of Wisconsin Press, Madison.

Phillips, A., 1998. The nature of cultural landscapes - a nature conservation perspective. Landscape Res. 23 (1), 21-38.

Phillips, A., 2005. Landscape as a meeting ground: category V protected landscapes/ seascapes and world heritage cultural landscapes. In: Brown, J., Beresford, M., Mitchell, N. (Eds.), The Protected Landscape Approach: Linking Nature, Culture and Community. Island Press, Gland, pp. 19-36.

Poolman, M., Van De Giesen, N., 2006. Participation: rhetoric and reality: the importance of understanding stakeholders based on a case study in upper East Ghana. Int. J. Water Resour. D 22, 561-573.

Pretty, J.N., 1995. Participatory learning for sustainable agriculture. World Dev. 23, 1247-1263.

Prieur, M., Council of Europe, 2006. Landscape and social, economic, cultural and ecological approaches. In: Landscape and Sustainable Development: Challenges of the European Landscape Convention. Council of Europe Publishing, Strasbourg, pp. 11-28.

Prieur, M., Durousseau, S., Council of Europe, 2006. Landscape and public participation. Landscape and Sustainable Development: Challenges of the European Landscape Convention. Council of Europe Publishing, Strasbourg. 165-207.

Pullin, A.S., 2004. Do conservation managers use scientific evidence to support their decision-making? Biol. Conserv. 119, 245-252.

Pullin, A.S., Stewart, G.B., 2006. Guidelines for systematic review in conservation and environmental management. Conserv. Biol. 20 (6), 1647-1656.

Ribas-Mateos, N., 2005. The Mediterranean in the Age of Globalization: Migration, Welfare, and Borders. Transaction Publishers, New Jersey.

Ross, J.W., 1994. Health social work: narrowing the gulf between practice and academia. Health Soc. Work 19 (3), 154-156.

Rössler, M., 1995. Neue Perspektiven für den Schutz von Kulturlandschaften: Natur und Kultur im rahmen der Welterbekonvention. Geographische Rundschau 47 (6), 343-347.

Rössler, M., 2006. World Heritage cultural landscapes: a UNESCO flagship programme 1992-2006. Landscape Res. 31 (4), 333-353.

Rowe, G., Frewer, L.J., 2004. Evaluating public participation exercises: a research agenda. Sci. Technol. Hum. Val. 29 (4), 512-557.

Slocum, R., 1995. Power, Process and Participation. Intermediate Technology Publications, London.

Stedman, R., Beckley, T., Wallace, S., Ambard, M., 2004. A picture and 1000 words: using resident-employed photography to understand attachment to high amenity places. J. Leisure Res. 36, 580-606.

Steinmetz, R., Wivel, A., 2010. Small States in Europe: Challenges and Opportunities. Ashgate, Copenhagen.

Stevens, S., 1997. The legacy of Yellowstone. In: Stevens, S. (Ed.), Conservation through Cultural Survival. Island Press, Washington D.C.

Testa, J., Undated. The Thomson Reuters journal selection process. Thomson Reuters. Available at: http://wokinfo.com/benefits/essays/journalselection/ (Last accessed 02.10.) 
The World Bank, 2010. Country Classifications. Available at:. The World Bank http:// data.worldbank.org/about/country-classifications/country-and-lending-groups Last accessed February 2010.

Thomas, A., 1999. Introduction. In: Thomas, A., Chataway, J., Wuyts, M. (Eds.), Finding Out Fast: Investigative Skills for Policy and Development. Sage Publications London, pp. 1-18.

Thompson, I.D., Flannigan, M.D., Wotton, B.M., Suffling, R., 1998. The effects of climate change on landscape diversity: an example in Ontario forests. Environ. Monit. Assess. 49 (2), 213-233.
Tress, B., Tress, G., Décamps, H., d'Hauteserre, A., 2001. Bridging human and natural sciences in landscape research. Landscape Urban Plan. 57 (3-4), 137-141.

Wu, J., Hobbs, R., 2002. Key issues and research priorities in landscape ecology: an idiosyncratic synthesis. Landscape Ecol. 17 (4), 355-365.

Zimmerer, K.S., 2006. Cultural ecology: at the interface with political ecology - the new geographies of environmental conservation and globalization. Prog. Hum. Geog 30 (1), 63-78. 